\title{
ROBUSTNESS IN REGIONAL DEVELOPMENT STUDIES. THE CASE OF LITHUANIA
}

\author{
Willem Karel M. Brauers ${ }^{1}$, Romualdas Ginevičius ${ }^{2}$ \\ ${ }^{1}$ University of Antwerp, Birontlaan, 97, B2600 Antwerpen, Belgium \\ E-mail: willem.brauers@ua.ac.be \\ ${ }^{2}$ Vilnius Gediminas Technical University, Saulètekio al. 11, LT-10223 Vilnius, Lithuania \\ E-mail: romualdas.ginevicius@adm.vgtu.lt \\ Received 07 January 2008; accepted 27 February 2009
}

\begin{abstract}
The definition of robustness in econometrics, the error term in a linear equation, was not only broadened, but, in addition, moved to the meaning of common language: from a cardinal to a qualitative one: the most robust one, more robust than..., as robust as......, robust, weak robust, less robust than..., not robust, etc. Both interpretations are tested by an application on the Robustness in Regional Development, namely of the Lithuanian Regions. The computation of Regional Income, being an exponent of the welfare economy, is not sufficient for the measurement of the well-being of the regional population. The well-being economy goes farther. In the well-being economy, each individual would have to feel good concerning material wealth, health, education, all kind of security and concerning the environment. In other words, multiple objectives have to be fulfilled. Moreover, these different multiple objectives are expressed in different units. Weights are most of the time used to equalize these different units. However, introduction of weights means also introduction of subjectivity. In order to avoid this dilemma, the internal mechanical solution of a ratio system, producing dimensionless numbers, is preferred. In addition, this outcome creates the opportunity to use also a non-subjective reference point theory. The choice of the objectives is also non-subjective if all stakeholders are involved, or if all possible objectives are represented. This theory, which is called MOORA (Multi-Objective Optimization by Ratio Analysis), is applied to the different regions of Lithuania. A redistribution of income has to take place from the well-being Lithuanian regions to the poorer regions, but under limiting conditions and for well defined and eventually controlled projects.
\end{abstract}

Keywords: robustness, weights, ratio system, reference point theory, MOORA, regional development, redistribution of income, labour drain.

\section{Definition of robustness}

By 1953 , which is quite recent for statistics ${ }^{1}$, robust became a statistical term as "strong, healthy, sufficiently tough to withstand life's adversities" (Stigler 1973: 872). Nevertheless, already in 1969 the statistician Huber considered robustness as purely cardinal as a compromise between a normal distribution and its light deviations ${ }^{2}$. More recently the statisticians Casella and Berger (2002: 509) call a robust alternative the median absolute deviation for a sample $x_{1}, \ldots \ldots x_{n}$.

The error term in a linear equation is the starting point for the definition of robustness in econometrics (Darnell 1997: 355). In addition, robustness is not only linked to error terms or random variables but also to residual terms, slack and dummy variables, outliers, etc. Darnell (1997: 356) concludes: "given the somewhat arbitrary ad hoc nature of the robust estimators these approaches have had limited application in econometrics". Kennedy (1998: 298) recognizes the existence of robust estimators as "an estimator whose properties while not quite best", he continues: "the topic of robustness has become quite popular recently in econometrics, as researchers have become aware of the extreme sensitivity of some of their estimation procedures". More specificity is found by authors who consider robustness in forms of the error distribution (Rhodes and Fomby 1988), whereas Mills (1992) presents a Bayesian prediction test which is robust to certain forms of non-normality in the error distribution. Moreover, from the beginning Bayesian analysis has to be characterized as cardinal, nevertheless with a high grade of arbitrariness. This arbitrariness could be softened by considerations on robustness ${ }^{3}$. Anyway, cardinal numbers form also the basis of robustness in the Poisson distribution, the $t$ statistic and in sampling (Särndal et al. 1992).

However, we observe a move to a more vague and qualitative definition of robustness, namely to the meaning of common language ${ }^{4}$ : from a cardinal to- 
wards a nominal scale: the most robust one, more robust than..., as robust as......, robust, weak robust, less robust than..., not robust, etc.

A debate between Frisch (1933) and Tinbergen (1930) ensued as whether or not Tinbergen had estimated structural form representations robust to changes in policy regimes or reduced form representations not robust to shifting policy regimes (Heckman 1992: 878). Kreps (1990) maintains that more robustness is more important for bargaining theory than for auction theory as more information is available in the latter case than in the former. He esteems that robust predictions are crucial although the meaning given to robustness may depend on the context (Vincke 1999). Edin and Ohlson (1991) examine that institutional arrangements in the political process affect budget deficits. Sensitivity analysis indicates that the results are robust. Admati and Pfleiderer (1994) speak of robustness in financial contracting. Another qualitative approach of robustness is related to subjective probability by Machina and Schmeidler (1992). Dasgupta and Maskin (2008) maintain that the simple majority rule is the most robust voting rule.

Concluding remark that significance of robustness depends on the context can be specified in different ways. First, robustness can be considered as cardinal or as a nominal scale. Second, if robustness is indicated as vague or arbitrary is it also not the case with inference statistics (Hoel 1971 versus Hays 1974), probability theory (Hays 1974) and statistical specification (Intriligator 1978: 2; Matyas and Sevestre 1992 versus Thomas 1985: 71 and Wonnacott, R. J. and Wonnacott, T. H. 1970: 312)? Third, robustness is characterized by completeness being present in the statistical population, when defined as covering events and opinions which are present, as well as in the statistical universe with events and opinions not only present but also possible.

\section{Conditions of robustness in multi-objective methods}

The most robust multi-objective method has to satisfy the following conditions:

1) the method of multiple objectives in which all stakeholders are involved is more robust than this one in which only one decision maker or different decision makers defending only a limited number of objectives are involved. All stakeholders mean everybody interested in a certain issue. Consequently, the method of multiple objectives has to take into consideration consumer sovereignty too. The method taking into consideration consumer sovereignty is more robust than this one which does not respect consumer sovereignty;

2) the method of multiple objectives in which all non-correlated objectives are considered is more robust than this one in which only a limited number of objectives is considered;

3) the method of multiple objectives in which all interrelations between objectives and alternatives are taken into consideration at the same time is more robust than this one in which the interrelations are only examined two by two;

4) the method of multiple objectives which doesn't need external normalization is more robust than this one which needs a subjective external normalization. Consequently, the method of multiple objectives with inside normalization through the non-subjective dimensionless measures is more robust than this one which uses subjective weights (already introduced by Churchman et al. in 1957; Churchman and Ackoff 1954) or subjective non-additive scores like in the traditional reference point theory (Brauers and Zavadskas 2008: 168-170; Brauers 2004: 158-159);

5) the method of multiple objectives based on cardinal numbers is more robust than this one based on ordinal numbers:"an ordinal number is one that indicates order or position in a series, like first, second, etc." (Kendall and Gibbons 1990). The robustness of cardinality is based first on the saying of Arrow (1974): "Obviously, a cardinal utility implies an ordinal preference but not vice versa", and second on the fact that the four essential operations of arithmetic: adding, subtracting multiplication and division are only reserved for cardinal numbers (see Annex B);

6) the method of multiple objectives which uses the last recent available data as a base in the response matrix is more robust than this one based on earlier data;

7) once the previous six conditions are fulfilled, the use of two different methods of multi-objective optimization is more robust than the use of a single method; the use of three methods is more robust than the use of two, etc.

The Multi-Objective Optimization by Ratio Analysis Method (MOORA) satisfies the first six conditions. In addition, MOORA satisfies partially the seventh condition by using two different methods of multi-objective optimization. MOORA is the most robust method as no other method satisfies the seven conditions better. 


\section{The MOORA method}

The method starts with a matrix of responses of all alternative solutions to all objectives:

$$
x_{i j}
$$

with: $x_{i j}$ as the response of alternative $j$ on objective or attribute $i, i=1,2, \ldots, n$ as the objective or the attributes $j=1,2, \ldots, m$ as the alternatives.

In order to define objectives better we have to focus on the notion of attribute. Keeney and Raiffa (1993: 32) present the example of the objective "reduce sulfur dioxide emissions" to be measured by the attribute "tons of sulfur dioxide emitted per year". An objective and a correspondent attribute always go together. Consequently, when the text mentions "objective" the correspondent attribute is meant as well.

The MOORA method consists of two parts: the ratio system and the reference point approach.

\subsection{The ratio system as a part of MOORA}

We go for a ratio system in which each response of an alternative on an objective is compared to a denominator, which is representative for all alternatives concerning that objective ${ }^{5}$ :

$$
x_{i j}^{*}=\frac{x_{i j}}{\sqrt{\sum_{j=i}^{m} x_{i j}^{2}}}
$$

with: $x_{i j}=$ response of alternative $j$ on objective $i, j=1$, $2, \ldots, m ; m$ the number of alternatives, $i=1,2, \ldots n ; n$ the number of objectives, $x_{i j}{ }^{*}=$ a dimensionless number representing the normalized response of alternative $j$ on objective $i$.

Dimensionless Numbers, having no specific unit of measurement, are obtained, for instance, by multiplication or division. The normalized responses of the alternatives on the objectives belong to the interval $[0 ; 1]$. However, sometimes the interval could be $[-1 ; 1]$. Indeed, for instance in the case of productivity growth some sectors, regions or countries may show a decrease instead of an increase in productivity, i.e. a negative dimensionless number ${ }^{6}$.

For optimization, these responses are added in case of maximization and subtracted in case of minimization:

$$
y_{j}{ }^{*}=\sum_{i=1}^{i=g} x_{i j}{ }^{*}-\sum_{i=g+1}^{i=n} x_{i j}{ }^{*},
$$

with: $i=1,2, \ldots, g$ as the objectives to be maximized, $i=g+1, g+2, \ldots, n$ as the objectives to be minimized, $y_{j}{ }^{*}=$ the normalized assessment of alternative $j$ with respect to all objectives, $y_{j}{ }^{*}$ can be positive or negative depending on the totals of its maxima and minima.

An ordinal ranking of the $y_{j}^{*}$ shows the final preference. Indeed, cardinal scales can be compared in an ordinal ranking after Arrow (1974): "Obviously, a cardinal utility implies an ordinal preference but not vice versa".

\subsection{The reference point approach as a part of MOORA}

Reference Point Theory will go out from the ratios found in formula (2), whereby, a Maximal Objective Reference Point is also deduced. The Maximal Objective Reference Point approach is called realistic and non-subjective as the coordinates $\left(r_{i}\right)$, which are selected for the reference point, are realized in one of the candidate alternatives. In the example, A $(10 ; 100)$, B $(100 ; 20)$ and $C(50 ; 50)$, the maximal objective reference point $R_{m}$ results in: $(100 ; 100)$. The Maximal Objective Vector is self-evident, if the alternatives are well defined, as for projects in Project Analysis and Project Planning.

Given the dimensionless number representing the normalized response of alternative $j$ on objective $i$, namely $x_{i j}{ }^{*}$ of formula (2) and in this way arriving to:

$$
\left(r_{i}-x_{i j}^{*}\right),
$$

with: $i=1,2, \ldots, n$ as the attributes, $j=1,2, \ldots, m$ as the alternatives, $r_{i}=$ the $i^{\text {th }}$ coordinate of the reference point, $x_{i j}{ }^{*}=$ the normalized attribute $i$ of alternative $j$, then this matrix is subject to the Min-Max Metric of Tchebycheff (Karlin and Studden 1966) ${ }^{7}$ :

$$
\underset{(j)}{\operatorname{Min}}\left\{\operatorname{Max}_{(i)} / r_{i}-x_{i j}{ }^{*} /\right\}
$$

$\mid r_{i}-x_{i j}{ }^{*} /$ means the absolute value if $x_{i j}$ is larger than $r_{i}$, for instance by minimization.

Concerning the use of the maximal objective reference point approach as a part of MOORA some reserves can be made in connection with consumer sovereignty. Consumer sovereignty is measured with the community indifference locus map of the consumers (Brauers 2008b: 92-94). Given its definition the maximal objective reference point can be pushed in the nonallowed non-convex zone of the highest community indifference locus and will try to pull the highest ranked alternatives in the non-allowed non-convex zone too (Brauers and Zavadskas 2006: 460-461). Therefore 
an aspiration objective vector can be preferred, which moderates the aspirations by choosing smaller coordinates than in the maximal objective vector, and consequently can be situated in the convex zone of the highest community indifference locus. Indeed, stakeholders may be more moderate in their expectations. The coordinates $q_{i}$ of an aspiration objective vector are formed as:

$$
q_{i} \leq r_{i}
$$

$\left(r_{i}-q_{i}\right)$ being a subjective element we don't like to introduce subjectivity in that way again. Instead, a test shows that the min-max metric of Tchebycheff delivers points inside the convex zone of the highest community indifference locus (Brauers 2008b: 98-103).

\subsection{The importance given to an objective}

The normalized responses of the alternatives on the objectives belong to the interval $[0 ; 1]$ (see formula 2). Nevertheless, it may turn out to be necessary to stress that some objectives are more important than the other ones. In order to give more importance to an objective, its normalized responses on an alternative could be multiplied by a Significance Coefficient:

$$
\ddot{y}_{j}{ }^{*}=\sum_{i=1}^{i=g} s_{i} x_{i j}{ }^{*}-\sum_{i=g+1}^{i=n} s_{i} x_{i j}{ }^{*},
$$

with: $i=1,2, \ldots, g$ as the objectives to be maximized, $i=g+1, g+2, \ldots, n$ as the objectives to be minimized, $s_{i}=$ the significance coefficient of objective $i, \ddot{y}_{j}{ }^{*}=$ the normalized assessment of alternative $j$ with respect to all objectives with significance coefficients.

The Attribution of Sub-Objectives represents another solution. Take the example of the purchase of fighter planes (Brauers 2002). For economics, the objectives concerning the fighter planes are threefold: price, employment and balance of payments, but there is also military effectiveness. In order to give more importance to military defence, effectiveness is broken down in, for instance, the maximum speed, the power of the engines and the maximum range of the plane. Anyway, the Attribution Method is more refined than a significance coefficient method could be, as the attribution method succeeds in characterizing an objective better. For instance, for employment two sub-objectives replace a significance coefficient of two and in this way characterize the direct and indirect side of employment.

Of course, at that moment the problem is raised of the subjective choice of objectives in general, or could we call it robustness of a choice? The Ameliorated Nominal Group Technique, as explained in Brauers (2004: 44-60), will gather all stakeholders interested in the issue to determine the objectives in a non-subjective and anonymous way. The original Nominal Group Technique of Van De Ven and Delbecq (1971) was less robust as the ameliorated version, as this one excludes subjective wishes of the experts. Indeed, in the Ameliorated Nominal Group Technique the group is questioned about the probability of occurrence of an event. In this way the experts become more critical even about their own ideas. The probability of the group is found as the median of the individual probabilities. Finally, the group rating $(R)$ is multiplied by the group probability $(P)$ in order to obtain the effectiveness rate of the event $(E)$. The events are translated into objectives and selected in a robust way by the Delphi Technique (examples are given in Brauers (2008a; 2004: 40-44)).

\section{A target for regional economic policy in Lithuania}

\subsection{Which regional economic policy?}

In a country economic development can differ from region to region. Changes are possible in the following ways.

Firstly, no actions or not to a sufficient extent are taken to weaken the differences. For example, in 2002 five Lithuanian districts counted an emigration quota against five districts with an immigration quota (Ginevičius and Podvezko 2004: 11). In 2005, only the district of the capital Vilnius remained with an immigration quota (Statistics of Lithuania 2006). The capital of a country or another main city as the only attraction pole is a general world phenomenon, but has to be corrected.

Secondly, a policy of smoothing out the differences in economic development would try to equalize the average income in all regions by the way of transfer payments. The richer regions will see their average individual income decrease in favour of the average individual income in the poorer regions in order to come to the same average individual income at the national level. Even worse, in Belgium an income paradox took place. The average individual income in the richer region became smaller than the average individual income in the poorer region (Brauers 2004: 247-259; 1999). Consequently, the most dynamic region is punished. Its growth effort will go down, less 
transfer payments will be possible and everybody will be worse off. Therefore, a limitation of the redistribution would be better.

Thirdly, some past experiences may help in order to limit the redistribution of income. The debate is centralized around the aid to Western Europe by the Marshall Plan (1948-1950) and an eventual aid to Eastern Europe and China at that time. The last item concerned a proposition by Senator Mc Mahon of February 1950: "what the United States can afford". The yearly aid of the Marshall Plan could be estimated to $2 \%$ of Gross National Product, but inclusive of the other proposition would have been $31 / 3 \%$ of GNP (Mendershausen 1949; Polak 1954). However, the inflation in the US finished in 1948 and, in addition, there was a slight deflation tendency and zero economic growth in 1949 (U.S. Department of Commerce 1951). One may say, as a conclusion, that the figure of $31 / 3 \%$ of GNP is acceptable with zero growth and without inflation. Transfer payments may amount to $101 / 3 \%$ in case of the important economic growth of $5 \%$ and inflation of $2 \%$. On the contrary, in time of recession with a minus one percent of economic growth and inflation of $2 \%$, transfer payments are limited to $41 / 3 \%$. The redistribution of income, even when restricted, can ameliorate the interregional trade, resulting in a win-win situation for all regions.

A note on terminology is needed to clarify the issue. Gross Domestic Product (GDP) in a certain year is the value added created on the national territory, being a territorial concept. On the contrary, Gross National Product (GNP) is related to the civilians and the permanent residents of a nation. Interpolated for a region, the Gross Regional Domestic Product (GRDP) signifies the value added created on a regional territory during a given year, and the Regional Income (RI) means the value added created by the permanent residents of a region during that year. Consequently, for the computation of the transfer payments of a region the Regional Income has to be considered instead of the Gross National Product.

However, for the measurement of the well-being of the regional population the computation of the Regional Income is not sufficient. The RI per capita can be biased by the presence of individuals with a very high income and a large group of small income earners. Furthermore, RI is expressed in money units, being a typical exponent of the economics of welfare. The Economics of Welfare (the term was invented by professor Pigou (1920)) tries to bring material wealth for everybody (Beveridge 1944; 1942). However, the wellbeing economy goes further. In the well-being economy each individual would have to feel good concerning material wealth, health, education, all kind of security and concerning the environment. In other words, multiple objectives have to be fulfilled. Even more, multiple objectives, realized simultaneously, will measure well-being.

All the objectives are translated into money terms in the well known Cost-Benefit Analysis. In this analysis even benefits are expressed in the chosen monetary unit, either in a direct or in an indirect way. Ipso facto the net-benefit is either positive or negative. The proposed solution is then, either the acceptance of the project or the status quo ante. Anyhow, cost-benefit presents a materialistic approach, whereby for instance unemployment and health care are degraded to monetary items. Consequently, to keep the original units of the objectives is better. However, at that moment the problem is posed to make the different units comparable, which is the problem of Normalization. Therefore, sometimes weights are given to the different units. The choice of weights means the introduction of subjectivity even with expert evaluation. For instance, past research on Lithuanian regionalization was less conclusive due to the fact that weights had to be chosen (Ginevičius and Podvezko 2004: 12-13; Ginevičius et al. 2004: 8-11).

\subsection{The data on the Lithuanian regions}

Not only the method to handle the different objectives expressed in different units has to be non-subjective but also the choice of the objectives, starting with the data underlying the objectives. What is meant by 'nonsubjective'?

In physical sciences, a natural law dictates non-subjectivity without deviations. In human sciences, for instance in economics, an economic law will state the attitude of men in general with very exceptionally individual deviations. Outside these human laws in the human sciences unanimity or at least a certain form of convergence of opinion between all stakeholders, which means everybody concerned in a certain issue, will lead to non-subjectivity ${ }^{8}$. Consequently, the choice of the data concerning the Lithuanian regions, leading to the objectives, would mean bringing together the representatives of the national government, of the districts, of the inhabitants, of the workers and entrepreneurs and of the specialists from the academic world. 
Instead of this considerable undertaking the authors themselves made a broad choice of data in the different fields of interests. For instance, for migrations of population the emigration is taken as negative and the immigration as positive. Further the issues are considered:

- the unemployment rate;

- for income and expenditure: the municipal budget and the monthly earnings;

- for housing and other floor space: useful floor space and completed dwellings;

- for education: number of pre-schools and of schools;

- for production and commerce: animal production, investments, construction and retail trade;

- for justice: criminal offences.

The number of physicians is considered for health care. On the national level mostly the number of hospital beds is counted, which has no sense on the regional level as many patients prefer treatment in large towns sometimes outside their own district.

For pollution the following average emissions in $\mathrm{kg}$ and per $\mathrm{km}^{2}$ are taken into account: solid emissions, $\mathrm{SO}_{2}, \mathrm{NO}_{\mathrm{x}}, \mathrm{CO}$, volatile organic compounds (VOC) and some others.

We do not mention the greenhouse gas emission $\left(\mathrm{CO}_{2}\right)$ as Lithuania has still a reserve for 2020 of $15 \%$ above the 2005 figure $^{9}$. Consequently, we suppose that the Lithuanian regions also have no problem with the greenhouse effect.

On the other side, Lithuania has to foresee energy from renewable sources for 2020 of $23 \%$ of its final energy demand (Commission of the European Communities 2008a). Table 1 shows all the data.

As mentioned above, in order to determine the transfer payments between the regions, the size of the Regional Income (RI) of each region has to be taken into account. The RI means the value added created by the permanent residents of a region during a year. The average gross monthly earnings for 2005 as mentioned in Table 1, sub 5 approaches more or less the notion of Regional Income. Table 2 classifies the regions by this notion.

However, the computation of the Regional Income is not sufficient. The RI per capita could be biased. Furthermore, regional income is a typical exponent of the welfare economy. The well-being economy goes further. In the well-being economy each individual would have to feel good concerning material wealth, health, education, all kind of security and concerning the environment. Therefore, multiple objectives have to be fulfilled. Multiple objectives, realized simultaneously, will measure well-being. The 16 data of Table 1 become attributes and when optimized, either as maxima or minima, objectives. At that moment, the MOORA method will be operational.

\section{Application of the MOORA method on the data of the Lithuanian regions}

\subsection{The part of the Ratio System in MOORA}

In order to apply the MOORA program the data of Table 1 are rearranged in Subtable $3 \mathrm{a}$ as objectives under the form of a matrix.

Next, in Subtables $3 b$ and $3 c$ starts from the matrix as in formula (2).

In addition, after formula (3) the objectives are then added in case of maximization and subtracted in case of minimization (Subtable 3c).

The last column of Subtable 3c gives the final ranking for the ratio system in MOORA.

\subsection{The part of the reference point theory in MOORA (Subtables 3d and 3e)}

Reference Point Theory starting from the dimensionless numbers of Table $3 \mathrm{c}$ is non-subjective, also by using the Maximal Objective Reference Point, as expressed in formula (5).

The last column of Subtable 3e gives the final rank for the Reference Point Theory in MOORA.

Comparing Subtables $3 \mathrm{c}$ and $3 \mathrm{e}$ the ranking is quite similar for the head and tail of the last column. However, the remark could be made that only the data for one year are observed. Therefore, having the figures for 2002 (Ginevičius and Podvezko 2004), a comparison is possible with that year (data are given in Annex A). In that manner the 2002 pre-European Union year is compared to a European Union year, namely 2005.

In Table 4 the income approach represents the measurement of the welfare of a region but not of the wellbeing of the inhabitants. The well-being is rather effectively measured by MOORA using the multiple objectives concerning these inhabitants. MOORA shows some differences between the ratio system and the reference point versions. Nevertheless, a general tendency is present, even compared with a pre-European Union year. Three well-being regions, Vilnius, Klaipeda and Kaunas, are in sharp contrast with Taurage and Šiauliai, regions with rather poor well-being. 


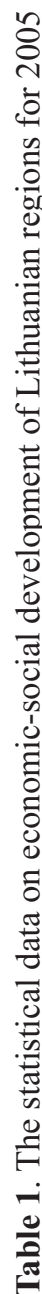

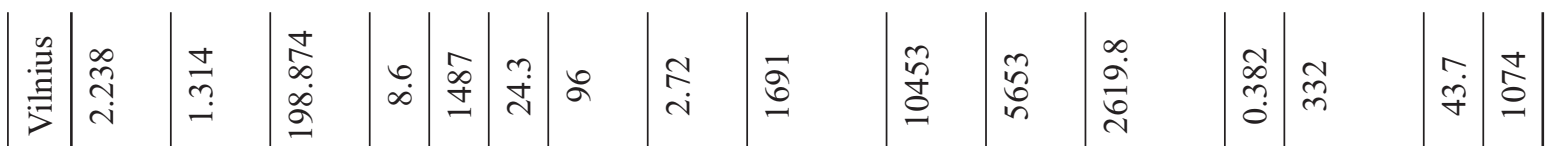

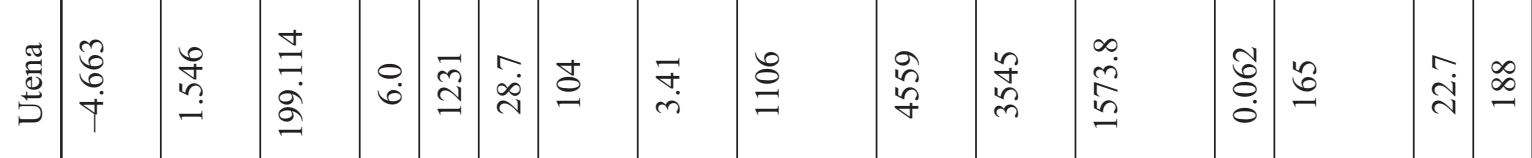

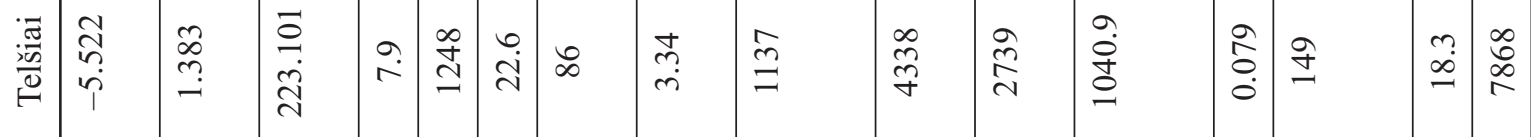

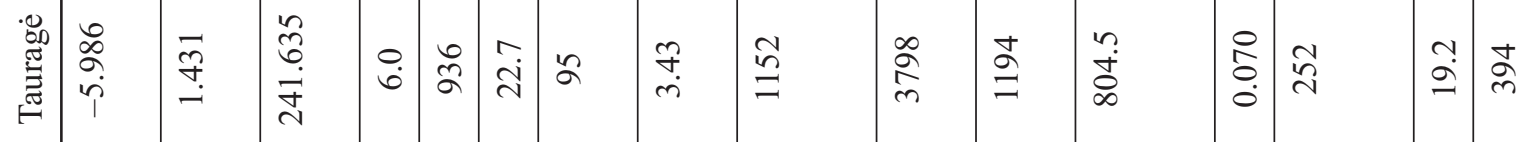

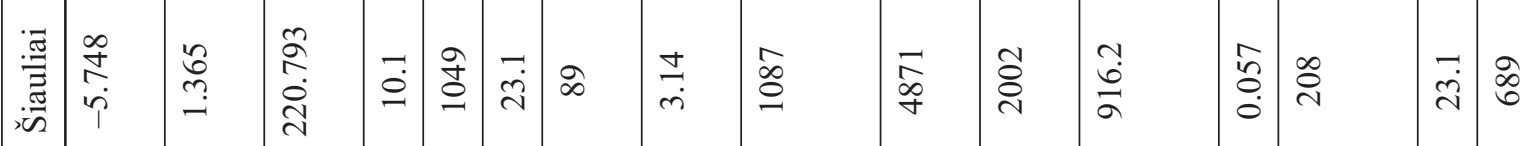

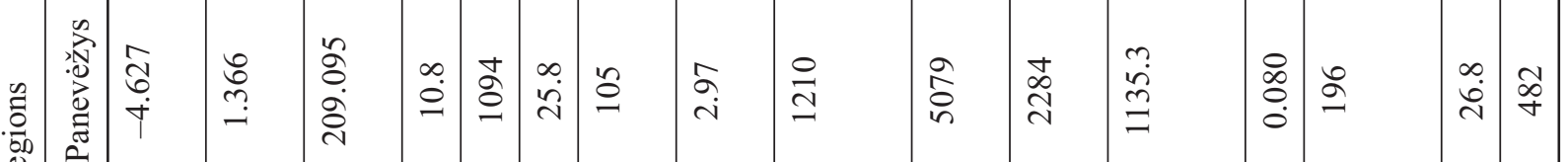
$\stackrel{\mathscr{C}}{\mathscr{2}}$

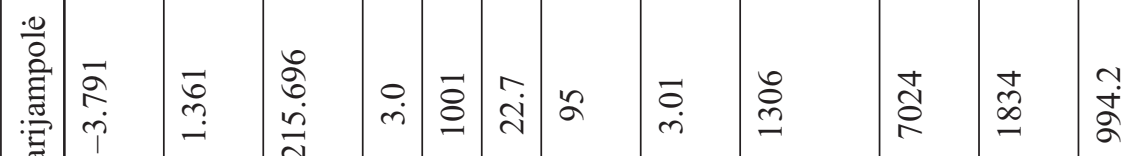

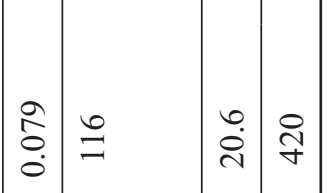

$\sum$

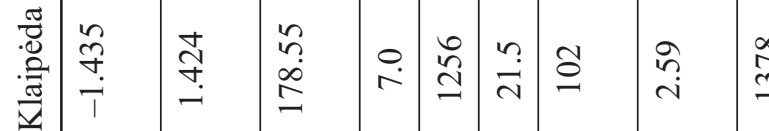

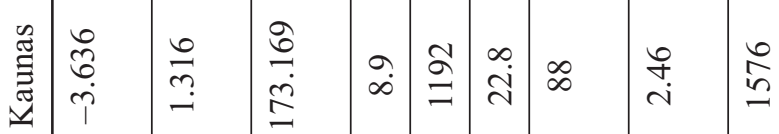

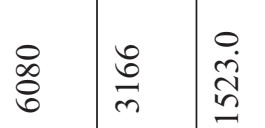

$\stackrel{\text { กิ }}{\infty}$

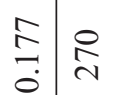

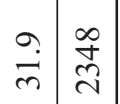

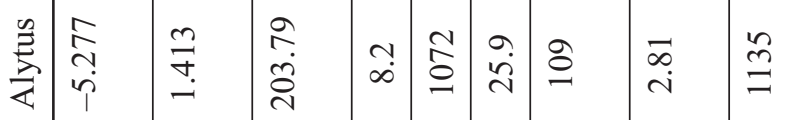

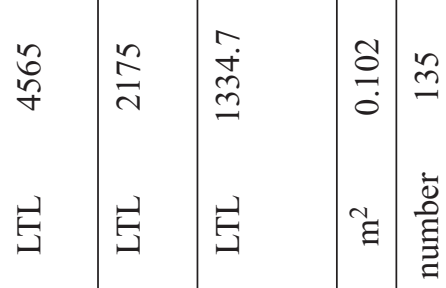

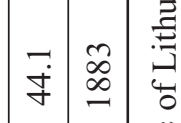

象导

离

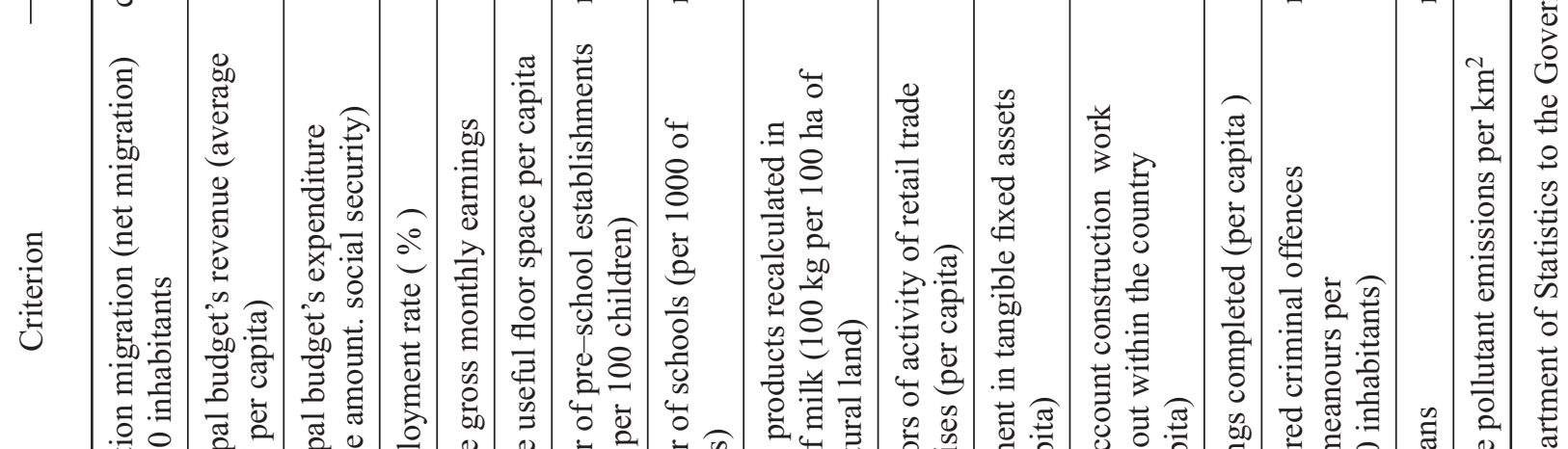

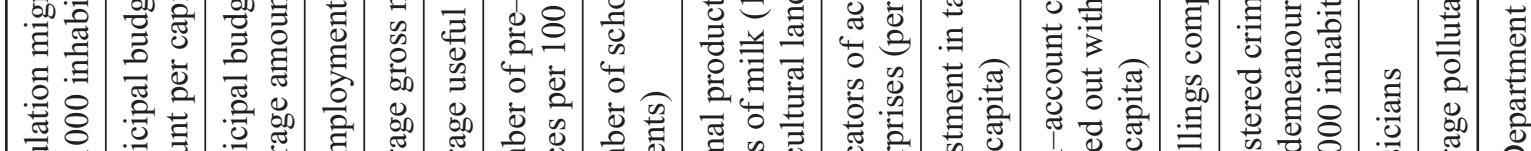

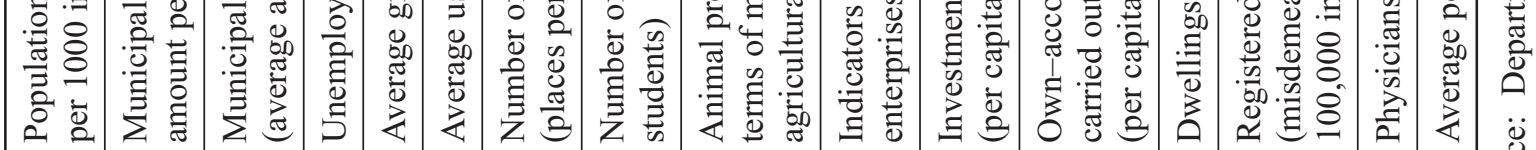

$\stackrel{\circ}{z}$

年

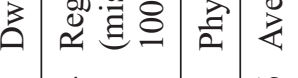




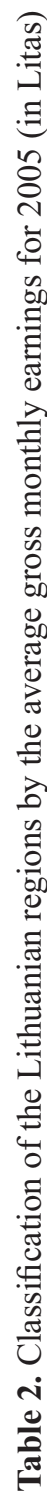

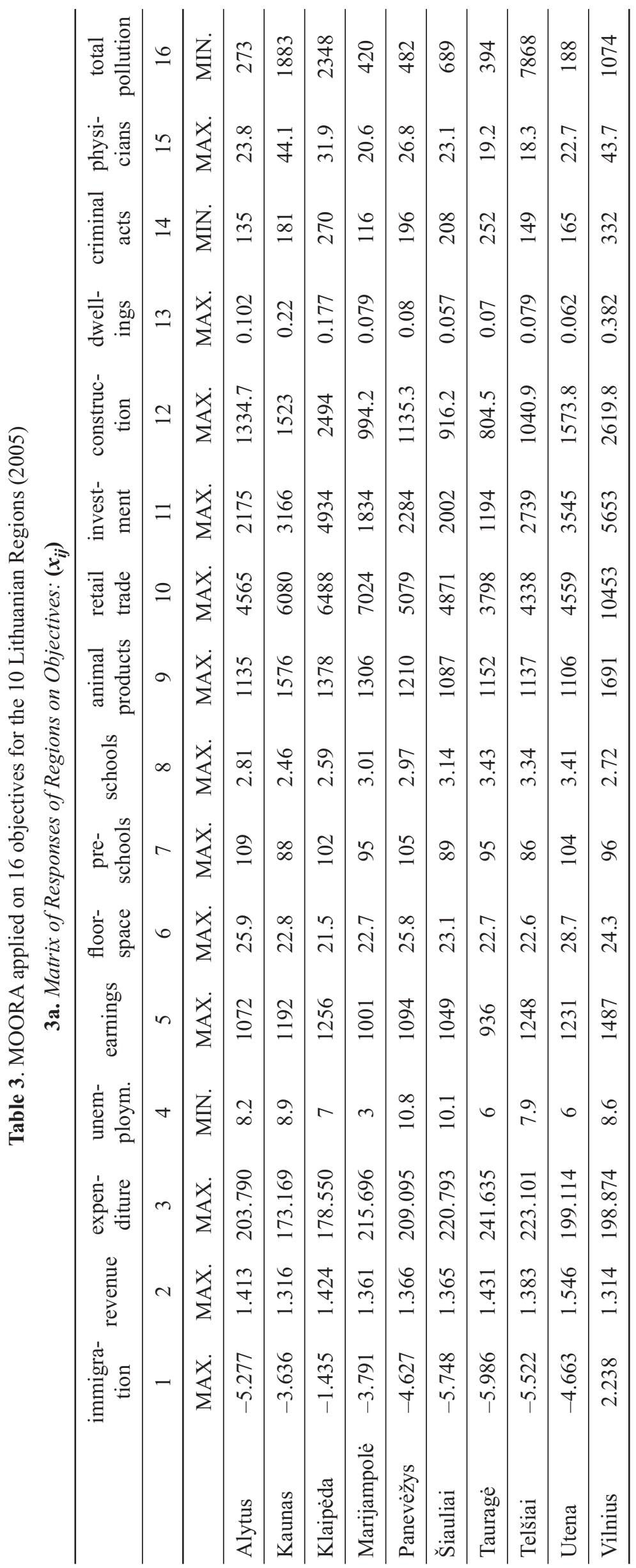




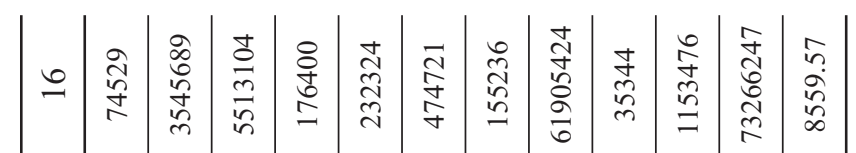

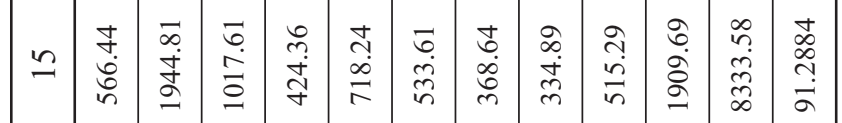

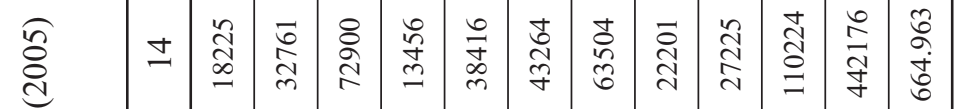

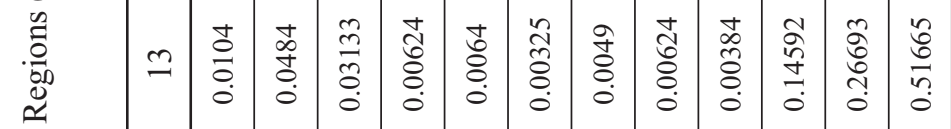

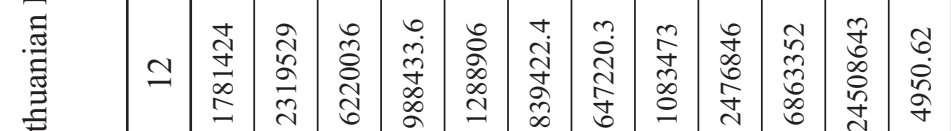

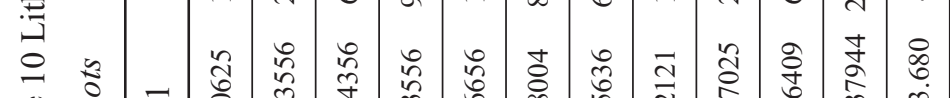

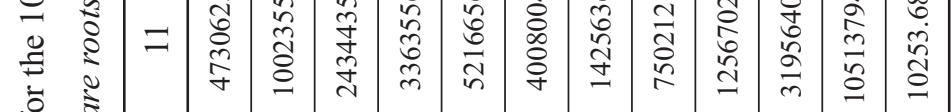

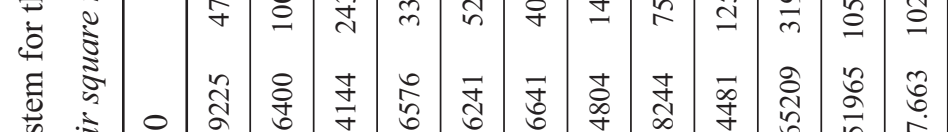

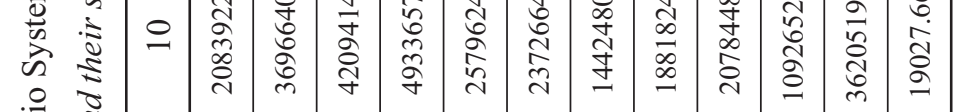

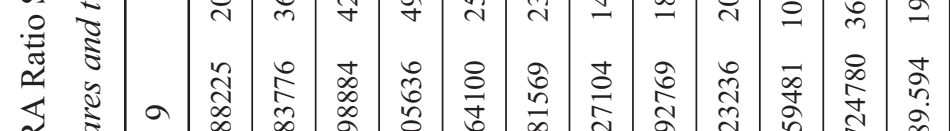

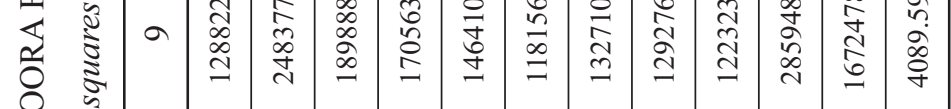

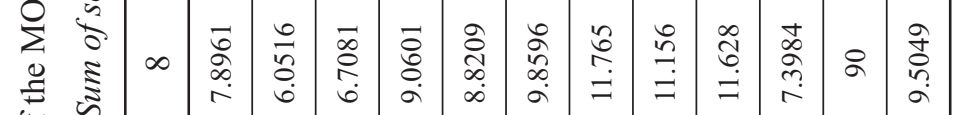

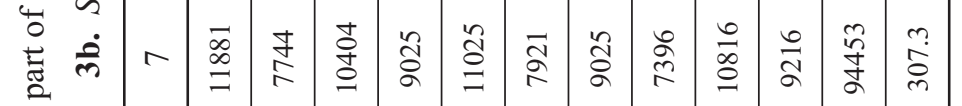

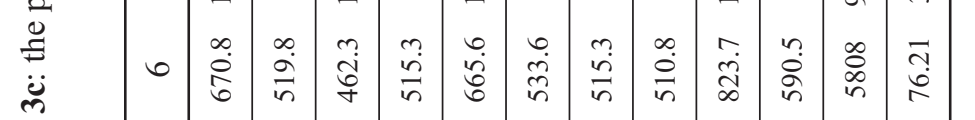

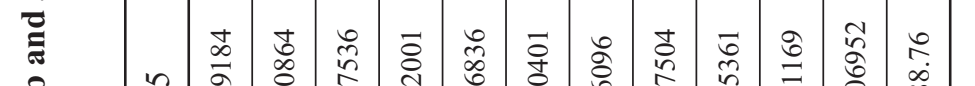

ले

$\frac{\frac{0}{0}}{\frac{0}{0}}$

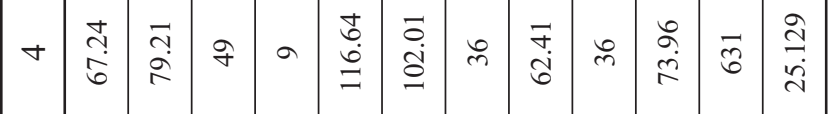

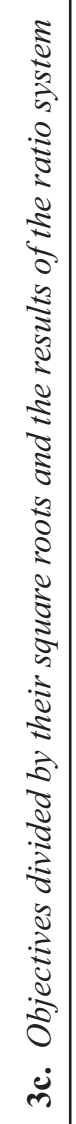

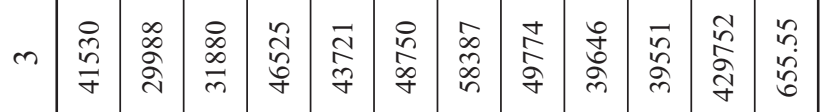

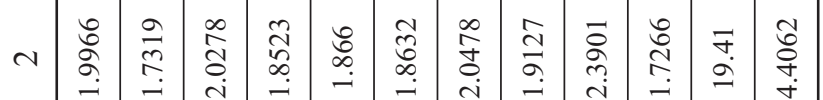

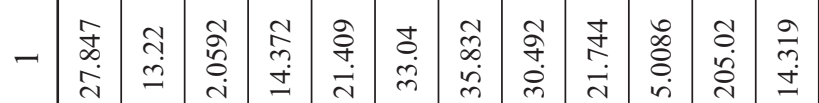

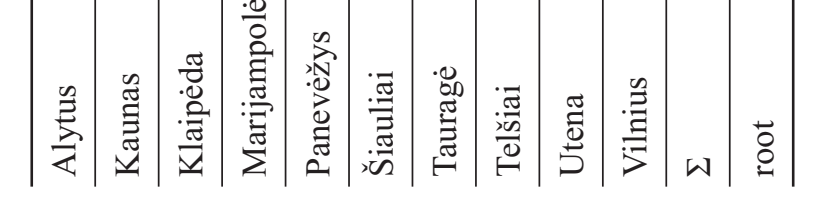

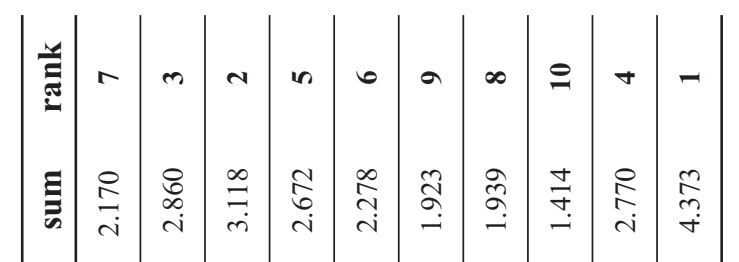

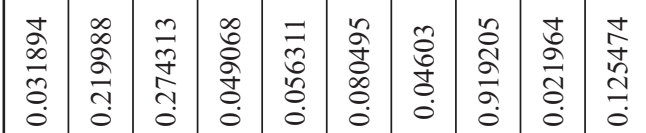

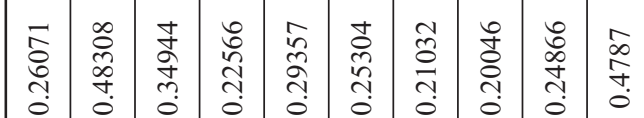

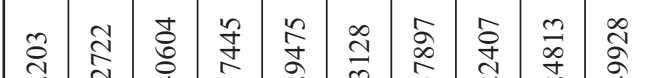

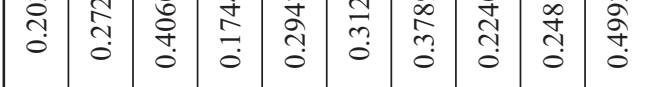

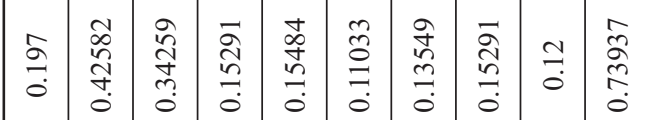

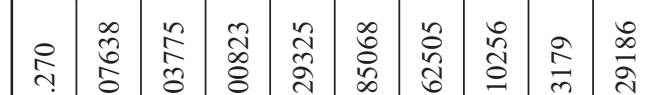

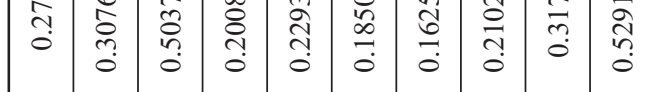

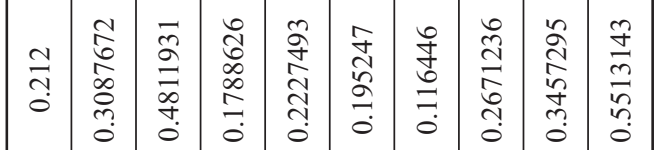

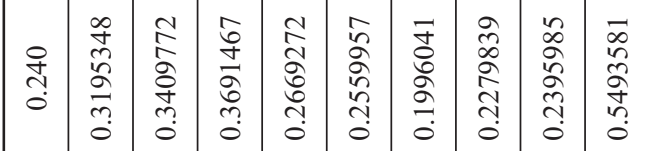

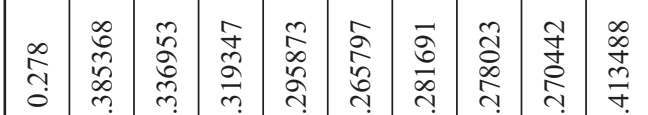

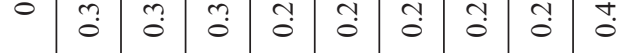

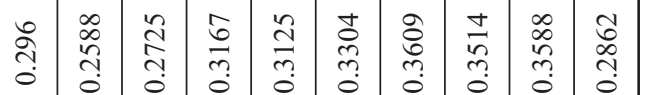

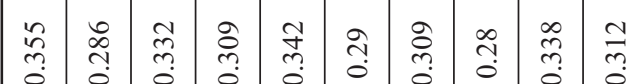

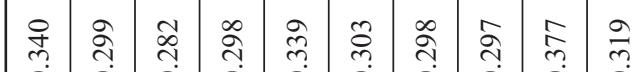

$\begin{array}{lllllllllllll}0 & 0 & 0 & 0 & 0 & 0 & 0 & 0 & 0 & 0\end{array}$

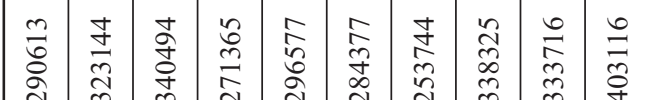

तิ तิ

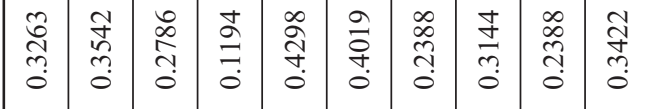

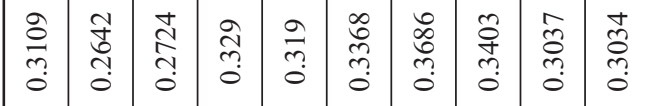

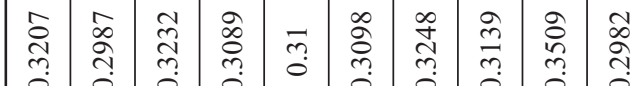

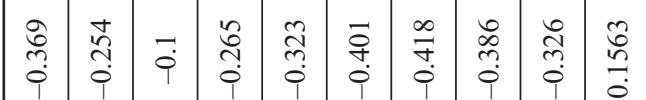

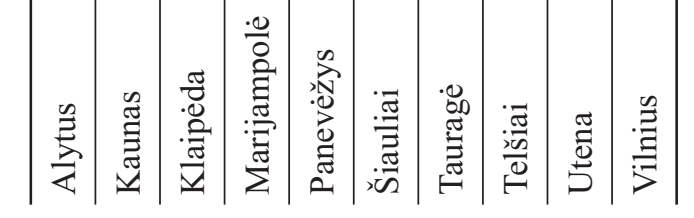




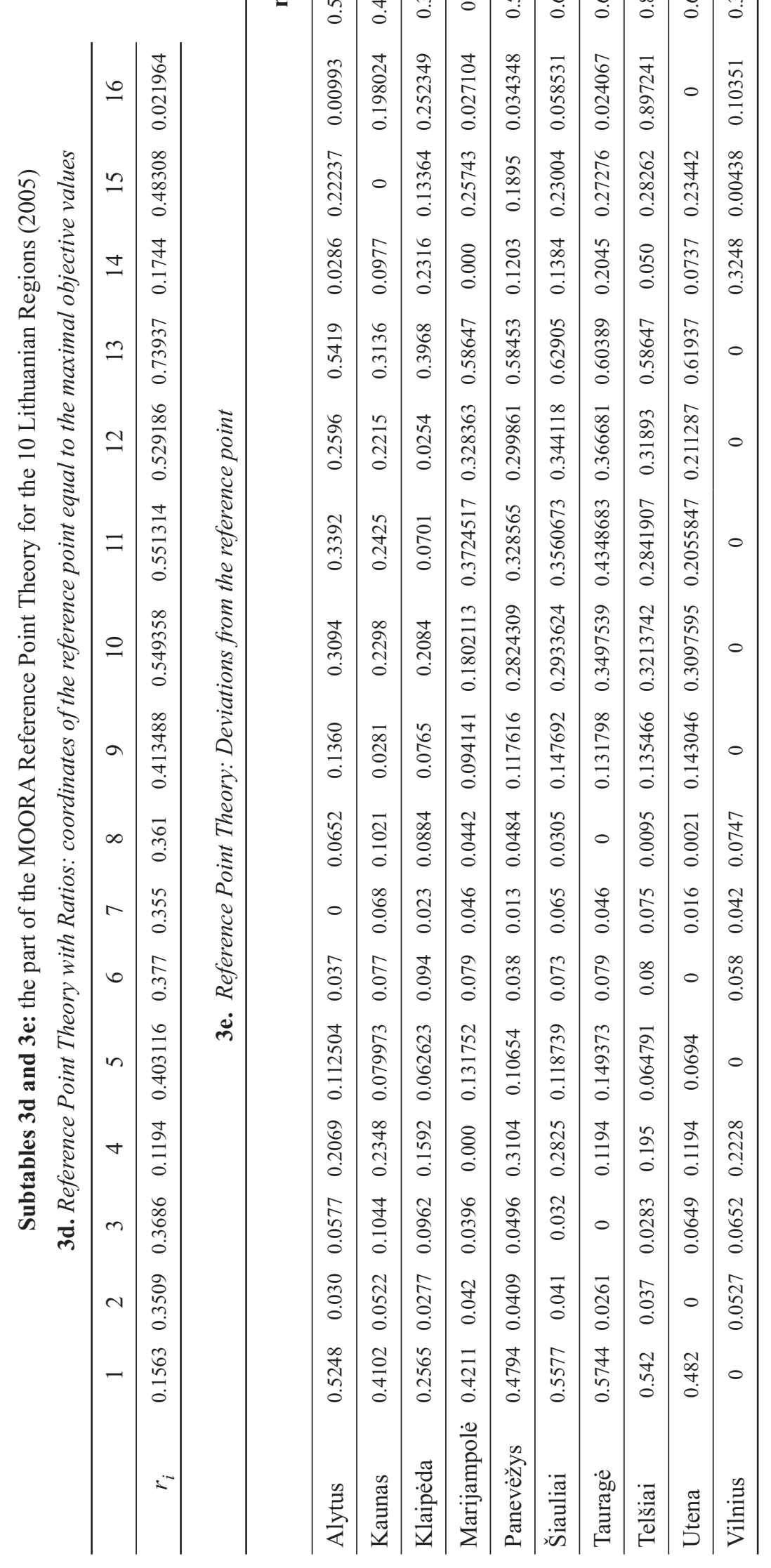

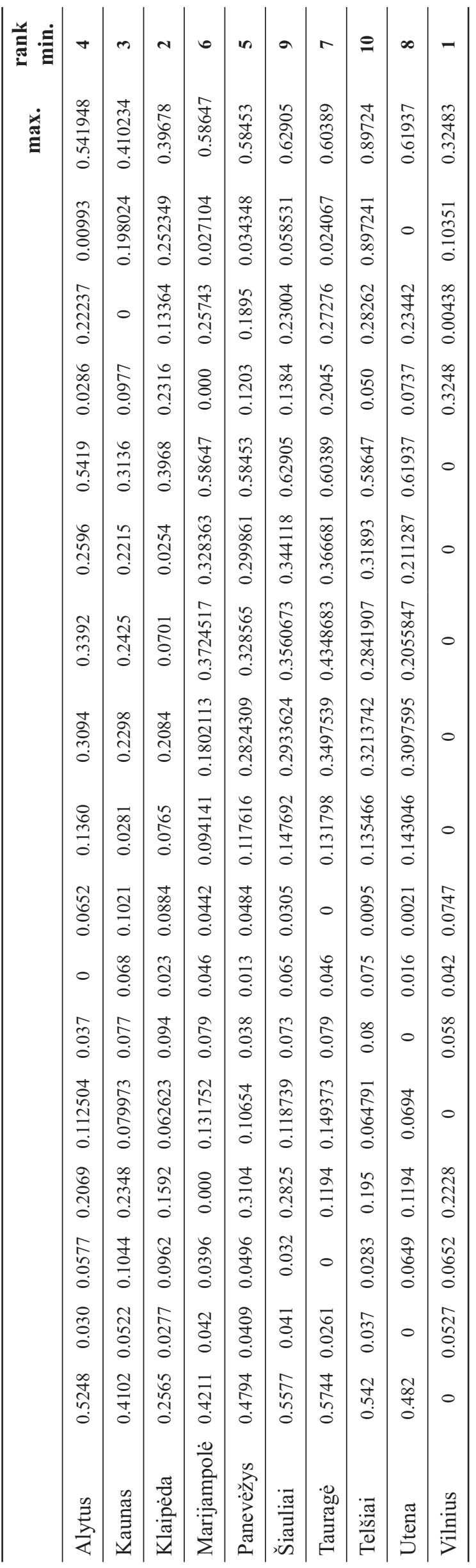


Table 4. Ranking of the Lithuanian Regions according to their well-being importance

\begin{tabular}{lccccc}
\hline Regions & Income & $\begin{array}{c}\text { MOORA } \\
\text { ratio system } \\
2005\end{array}$ & $\begin{array}{c}\text { MOORA } \\
\text { reference point } \\
2005\end{array}$ & $\begin{array}{c}\text { MOORA } \\
\text { ratio system } \\
2002\end{array}$ & $\begin{array}{c}\text { MOORA } \\
\text { reference point } \\
2002\end{array}$ \\
\hline Vilnius & 1 & 1 & 1 & 1 & 1 \\
\hline Klaipėda & 2 & 2 & 2 & 4 & 6 \\
\hline Kaunas & 5 & 3 & 3 & 2 & 2 \\
\hline Utena & 4 & 4 & 8 & 3 & 3 \\
\hline Marijampole & 9 & 5 & 6 & 5 & 5 \\
\hline Panevėžys & 6 & 6 & 5 & 6 & 8 \\
\hline Alytus & 7 & 7 & 4 & 10 & 4 \\
\hline Tauragé & 10 & 8 & 9 & 8 & 7 \\
\hline Šiauliai & 8 & 9 & 10 & 9 & 9 \\
\hline Telšiai & 3 & 10 & & & 7 \\
\hline
\end{tabular}

Telšiai is very poor concerning general well-being, but has sufficient income to ameliorate this anomaly. The anomaly is mainly brought about by pollution, emigration and shortage of dwellings. The pollution originates from the nearby town of Mažeikiai (Telšiai county) where the oil refinery of "Mažeikių nafta", the only oil refinery of the Baltic States, is located. In 2005 the refinery started with the introduction of an environment management system. The completion was scheduled for 2007 (Mažeikių nafta 2008).

The Reference Point Method shows some other deviations for regions, which can be self-supporting concerning well-being. For instance, Utena, shows a shortage of dwellings, for which it is as bad as Taurage and Šiauliai. Since 2002 there has also been a relative amelioration of the position of Klaipeda and of Panevèžys.

The labour drain to the district of Vilnius represents a serious problem. In 2002 an immigration surplus still existed in the regions of Alytus, Kaunas, Marijampole, Utena and Vilnius. In 2005 only the district of Vilnius showed an immigration surplus.

\section{Some conclusions on the economic policy of the Lithuanian regions}

The redistribution of income has to take place between the Lithuanian regions. The well-being regions, Vilnius, Klaipeda and Kaunas can eventually support the poorer regions, Taurage and Šiauliai, inside the limits mentioned above, namely $31 / 3 \%$ of the Regional Income of a rich region under conditions of zero economic growth and inflation. However, these transfer payments have to be diminished by the transfers given directly and indirectly (by the national state) to the European Union, to the other international institutions and by the aid to developing countries. Opposite, the transfer payments have to take into account the subsidies received from the European Union and from the other international institutions. Anyway, sometimes an overlapping is possible between the transfer payments from Europe and from the other regions. In the long run it would be better that all transfer payments are centralized by the European Union itself.

As already said, the poorer regions concern especially Šiauliai and Tauragè. Regional aid to them is best project oriented. These projects can be inspired by studying the data of Table 4 . Also, the international organizations only allot assistance for a specific project, even with the privilege to follow up the advancement of the project.

Šiauliai needs more employment opportunities and more investments, which at the same time will decrease the emigration of the inhabitants. Taurage with the highest emigration quota of the country has to attract more investments with more construction also for private housing. The retail trade has to be developed, for instance around an important highway, when trade with Russia could develop.

However, economic development is necessary over the whole of the Lithuanian territory with the exception of the district of Vilnius. The labour drain to Vilnius will still further increase when Vilnius is the cultural capital of Europe. Development of tourism all over the Lithuanian territory would be good. Fishing in the many lakes and fitness centers around the lakes will 
certainly attract foreign tourists. The rocket base near Plateliai (Telšiai) can be an attraction pole for all European and Turkish tourists as they were threatened by the rockets one day. Even a later closed nuclear power plant of Ignalina of the type of Chernobyl, if safely protected, can attract disaster tourists and industrial archeologists, industrial archeology being the last modern branch of modern history. Nevertheless, not only services are needed but also a form of industrialization.

As already mentioned, the European Commission foresees a $23 \%$ part of renewables in the final energy demand of Lithuania by 2020. These renewables could come from non-fossil energy sources: wind, solar, geothermal, wave, tidal, hydropower, biomass, landfill gas, sewage treatment plant gas and biogases. The European Commission remarks: "they are related to the promotion of local employment and opportunities for small and medium-sized enterprises, regional and rural development, stimulating economic growth and increasing global European industry leadership" (Commission of the European Communities 2008b). Anyway it would mean an opportunity for industrialization of the Lithuanian regions.

\section{General conclusions}

The remark that significance of robustness depends on the context is specified in different ways. First, robustness can be considered either as cardinal or as a nominal robust. Second, if robustness is indicated as vague or arbitrary perhaps it is also the case with inference statistics, probability theory and statistical specification. Third, robustness is characterized by completeness being present in the statistical population covering events and opinions which are present, as well as in the statistical universe with events and opinions not only present but also possible.

Concerning the most robust method of multi-objective optimization the following conditions are to be satisfied:

1) the method of multiple objectives in which all stakeholders are involved is more robust than one in which only one decision maker or different decision makers defending only a limited number of objectives are involved. All stakeholders mean everybody interested in a certain issue. Consequently, the method of multiple objectives which takes into consideration consumer sovereignty is more robust than this one which does not respect consumer sovereignty. Consumer sovereignty is measured with com- munity indifference loci. Solutions have to deliver points inside the convex zone of the highest community indifference locus;

2) the method of multiple objectives in which all non-correlated objectives are considered is more robust than this one in which only a limited number of objectives is considered;

3) the method of multiple objectives in which all interrelations between objectives and alternatives are taken into consideration at the same time is more robust than this one in which the interrelations are only examined two by two;

4) the method of multiple objectives which does not need separate normalization is more robust than this one which needs a subjective separate normalization. Consequently, a method of multiple objectives which uses non-subjective dimensionless measures with inside normalization is more robust than this one which for normalization uses subjective weights or subjective nonadditive scores like in the traditional Reference Point Theory;

5) the method of multiple objectives based on cardinal numbers is more robust than this one based on ordinal numbers: an ordinal number is one that indicates order or position in a series, like first, second, etc.. The robustness of cardinality is based on the saying of Arrow (1974): "Obviously, a cardinal utility implies an ordinal preference but not vice versa", and also on the fact that the four fundamental operations of arithmetic: adding, subtracting, multiplication and division are only reserved for cardinal numbers;

6) the method of multiple objectives which uses the last recent available data as a base in the response matrix is more robust than this one based on earlier data;

7) once the previous six conditions are fulfilled, the use of two different methods of multi-objective optimization is more robust than the use of a single method; the use of three methods is more robust than the use of two, etc.

The Multi-Objective Optimization by Ratio Analysis Method (MOORA) satisfies the first six conditions. In addition, MOORA satisfies partially the seventh condition by using two different methods of Multi-Objective Optimization. MOORA is the most robust method as no other method satisfies the seven conditions better. For all these reasons we selected MOORA.

In a country economic development can differ from region to region. A policy of smoothing out the dif- 
ferences in economic development may not result in a killing disadvantage for the richer regions. On the contrary, an eventual redistribution of income has to be a win-win-operation.

Next question is how to measure this redistribution. The computation of the Regional Income, being an exponent of the welfare economy, is not sufficient for the measurement of the well-being of the regional population. A well-being economy goes further than a welfare economy. In the well-being economy each individual would have to feel good concerning material wealth, health, education, all kind of security and concerning the environment. in other words, multiple objectives have to be fulfilled. However, these different multiple objectives are expressed in different units, which means that a problem of normalization is posed. For this purpose the attribution of weights, scores or exponents can be used, which means introduction of subjectivity. Therefore, an internal mechanical procedure is operated in order to escape from that subjective problem, namely Multi-Objective Optimization by Ratio Analysis (MOORA). Dimensionless numbers obtained in this manner will also form the basis for Reference Point Theory, the second part of MOORA.

Given all the objectives MOORA measures finally the well-being differences between the ten regions of Lithuania. Three well-being regions are in sharp contrast with two regions with a rather poor well-being. The other regions are more self-supporting concerning general well-being. In addition, the labour drain to the district of Vilnius from all the other regions represents a serious problem.

The redistribution of income has to take place inside certain limits, whereas commercialization and industrialization of the regions has to occur, beside the three regions already doing well where well-being is concerned.

Does the regional application of Lithuania satisfy the seven conditions of robustness?

\section{1) First condition of robustness}

The choice of the objectives and their respective importance has to be made by all the stakeholders involved in the issue. As this procedure is rather cost and timeconsuming the authors have taken the responsibility to choose objectives for all the regions. Consequently, this condition also respects consumer sovereignty.

\section{2) Second condition of robustness}

All objectives were taken into consideration as much as possible. The choice of the objectives for all the regions is represented in the fields of migration of the population between the regions, the unemployment rate, income and expenditure, housing and other floor space problems, education, production, commerce, justice and health care problems. For pollution the following average emissions in $\mathrm{kg}$ and per $\mathrm{km}^{2}$ are taken into account: solid emissions, $\mathrm{SO}_{2}, \mathrm{NO}_{\mathrm{x}}, \mathrm{CO}$, and volatile organic compounds. The greenhouse effect $\left(\mathrm{CO}_{2}\right)$ is not included as Lithuania may still exceed its actual emission level. On the contrary, the production of renewable energy will form an opportunity for further industrialization of Lithuania. Significance coefficients are too subjective to characterize the importance of an objective. Instead, sub-objectives, heightened to objectives, were introduced in order to give importance to a certain objective.

\section{3) Third condition of robustness}

All interrelations between objectives and alternatives were involved at the same time under the form of a matrix of responses considered as a whole and as a starting point for the application of MOORA.

\section{4) Fourth condition of robustness}

The use of dimensionless measures is a more robust method than subjective methods of normalization. In the application MOORA's dimensionless ratios satisfied this condition. Significance coefficients are too subjective to characterize the importance of an objective. Instead, sub-objectives, heightened to objectives, are introduced in order to give importance to a certain objective.

\section{5) Fifth condition of robustness}

The method of multiple objectives based on cardinal numbers is more robust than this one based on ordinal numbers. The application was entirely based on cardinal numbers.

\section{6) Sixth condition of robustness}

The last available data were used. Perhaps more recent raw data exist, but regrouping, aggregation and overlapping of data was not done up until now.

\section{7) Seventh condition of robustness}

All the previous six conditions are fulfilled and also the seventh condition as two different methods of MultiObjective Optimization were used. No other Multi-Objective Optimization Method exists which uses more than two Multi-Objective Optimization Methods and fulfill the previous six conditions.

In this way the regional research on Lithuania satisfies all conditions on robustness. 


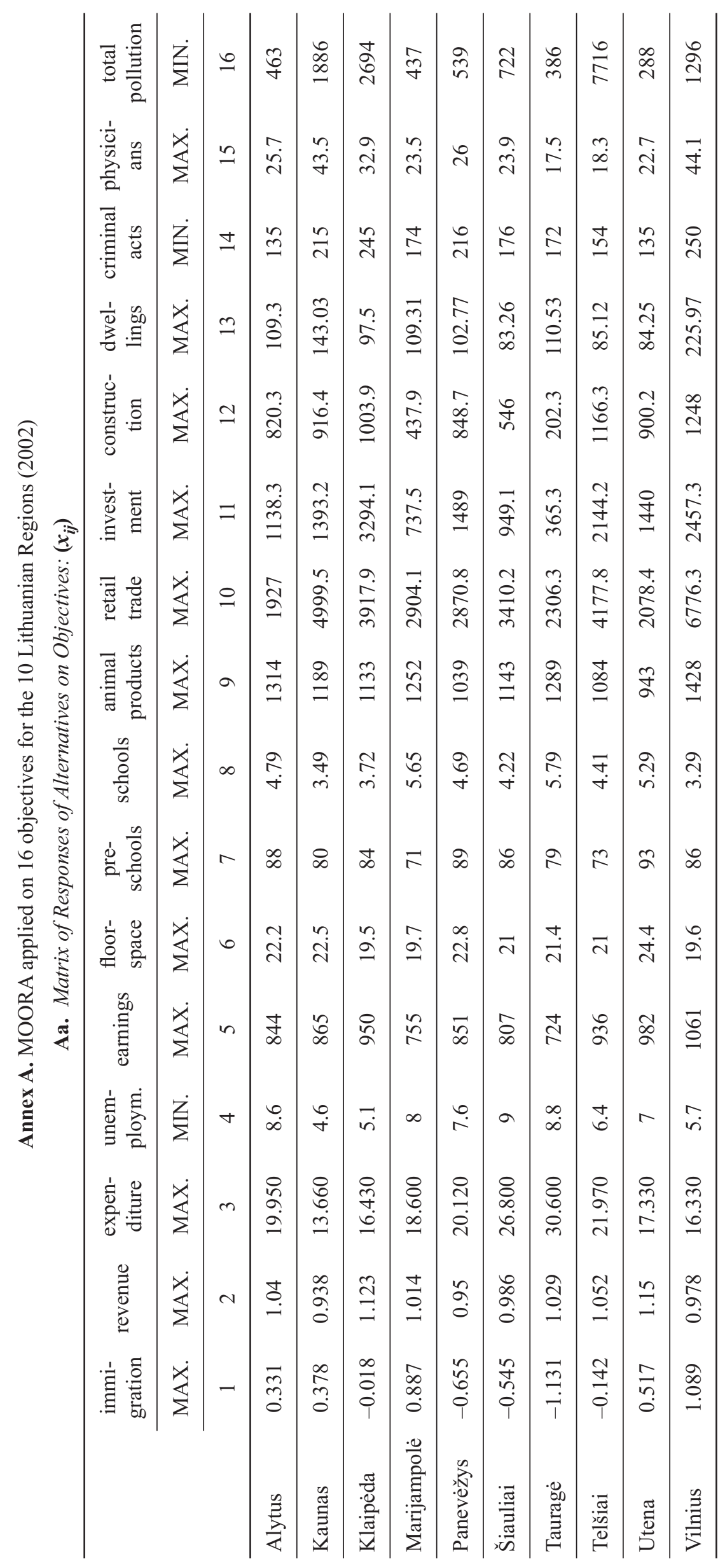




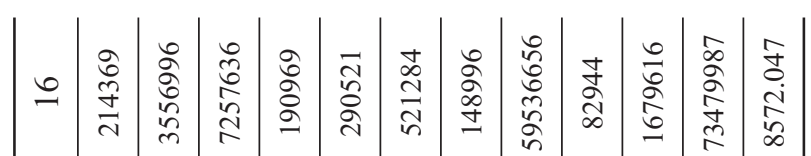

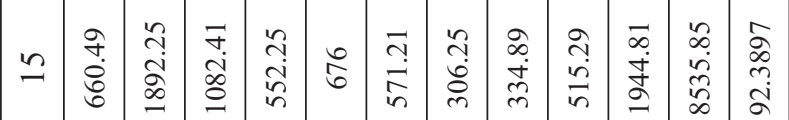

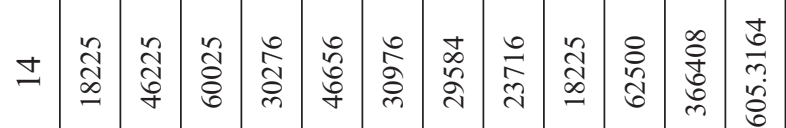

สิธి

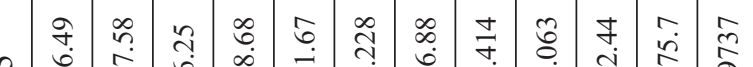

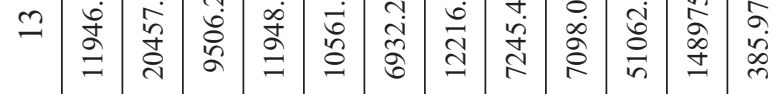

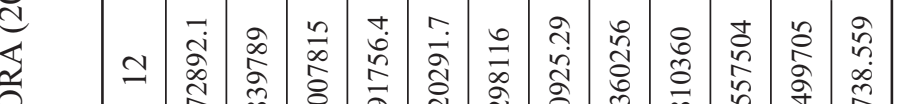
$\sum^{0}$

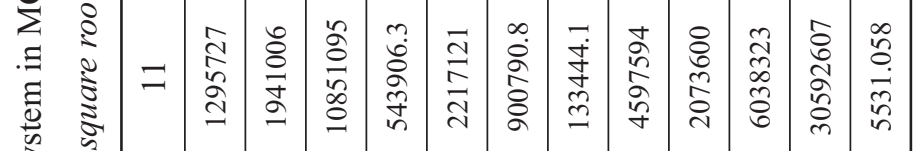

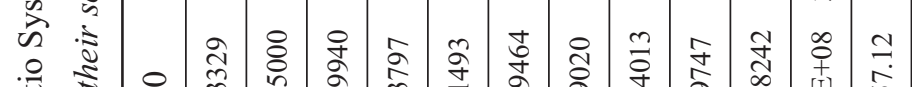

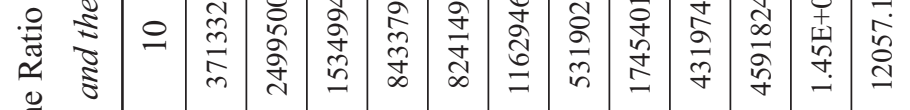

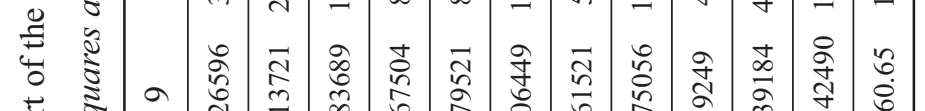

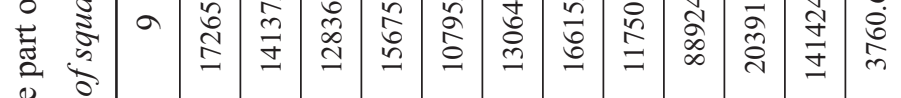

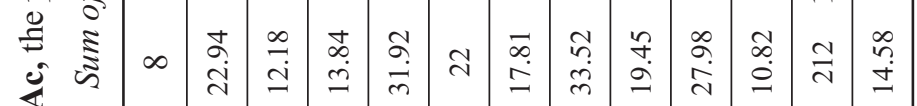

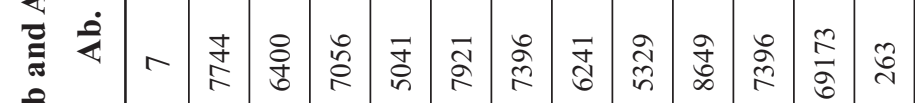

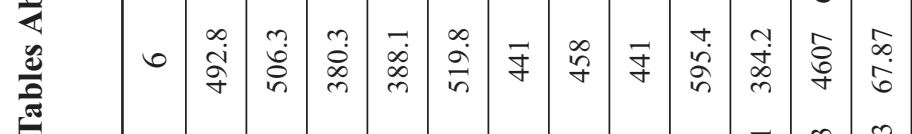
ก

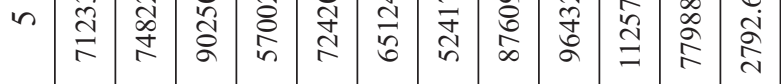

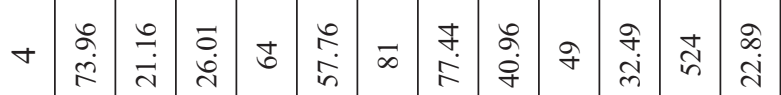

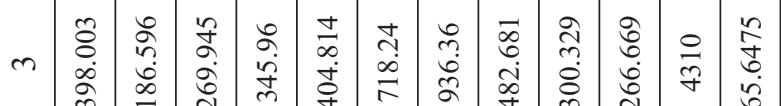

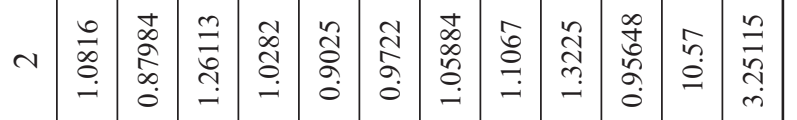

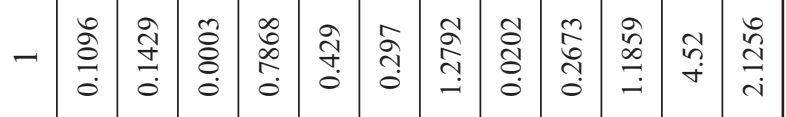

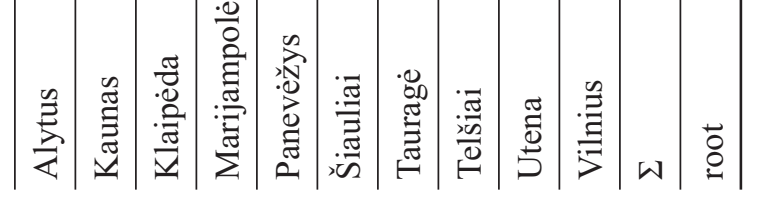

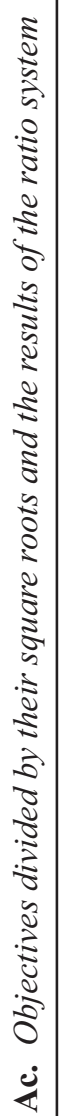

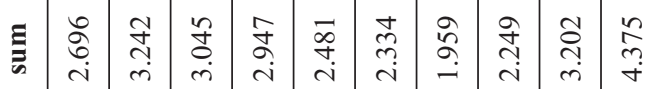

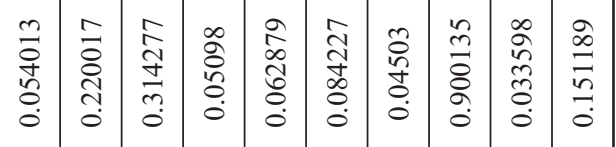

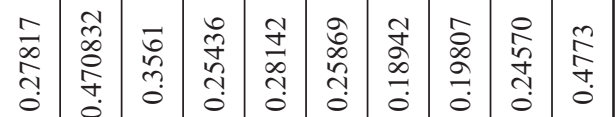

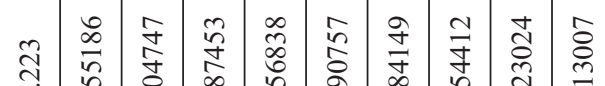

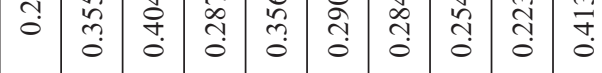
๓

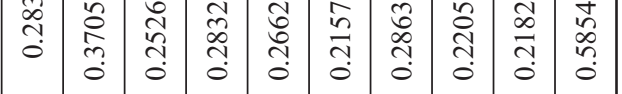

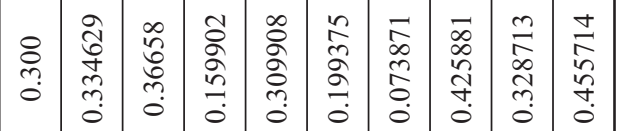

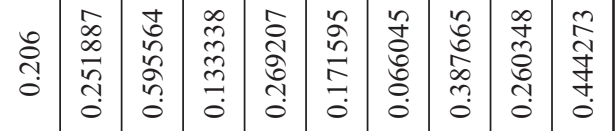

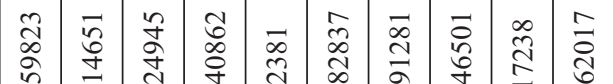

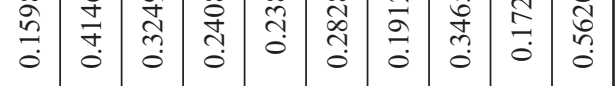

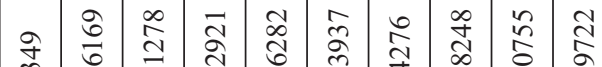

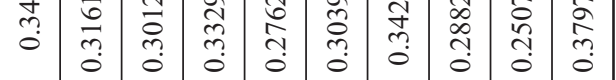

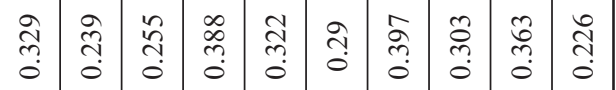

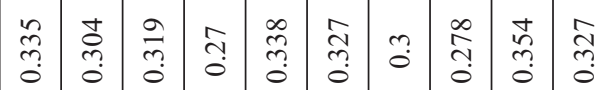

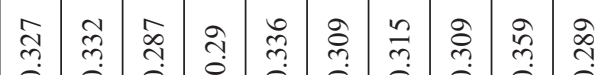

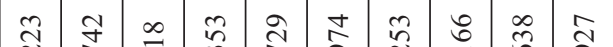

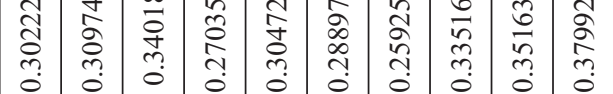
$\begin{array}{llllllllllll}0 & 0 & 0 & 0 & 0 & 0 & 0 & 0 & 0 & 0\end{array}$

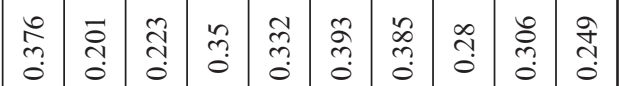

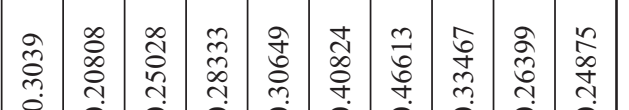
$\begin{array}{lllllllll}1 & 0 & 0 & 0 & 0 & 0 & 0 & 0 & 0\end{array}$

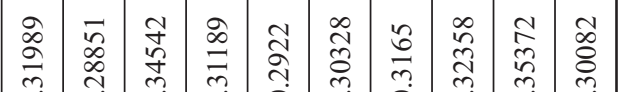
m.

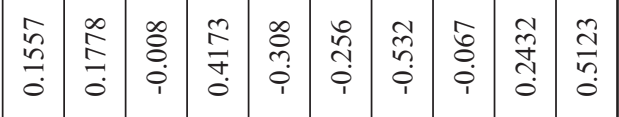

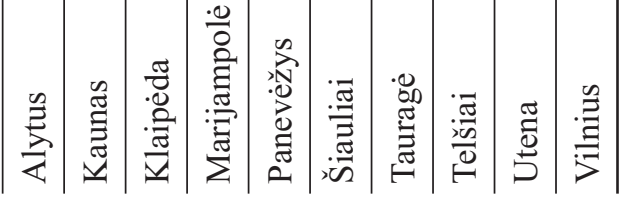




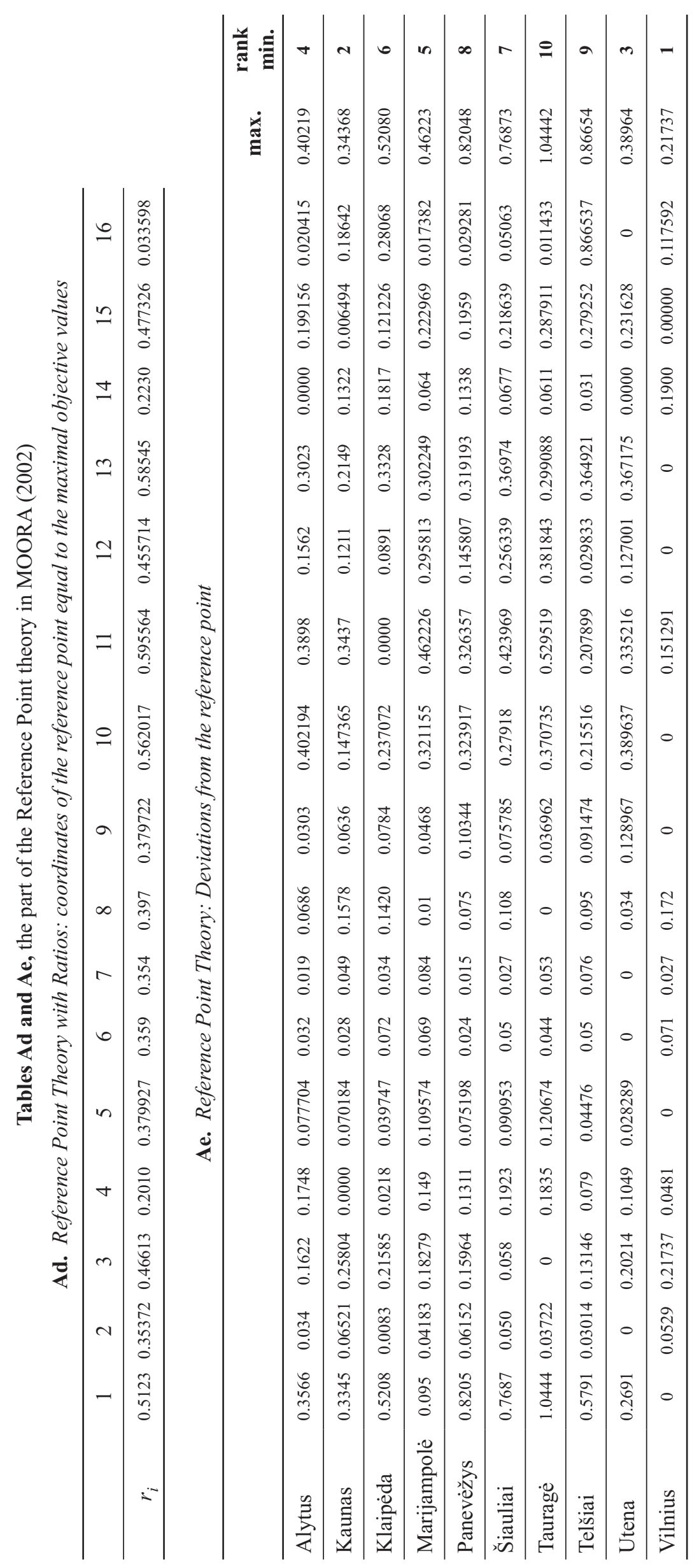




\section{Annex B}

\section{Ordinal Numbers and Rank Correlation Methods}

The statistician Kendall wrote in 1948 (p. 1), even repeated in 1990 (Kendall and Gibbons):"we shall often operate with ordinal numbers as if they were the cardinals of ordinary arithmetic, adding them, subtracting them, and even multiplying them", but he never put this statement into practice at least for subtraction and multiplication.

The method of correlation of ranks, consisting of totalizing ranks of ordinal numbers, can it be considered for banning subjectivity? Rank correlation was introduced first by psychologists such as Spearman (1904, 1906, 1910) and later taken over by the statistician Kendall in 1948. Kendall (1948: 87) gave the following example after a kind of Lexicographic Method. $\mathrm{C}$ is ranked first because it has two firsts, $G$ has the remaining first and then B is ranked third as it has two seconds, etc. Then Kendal proved that "this procedure is not selfconsistent".

Let us illustrate this inconsistency with the question: "how to choose a wife?" The first choice is a woman extremely beautiful and extremely good in cooking but extremely stupid. The second choice is the extraordinary intelligent woman, but extremely ugly and extremely bad in cooking. The woman who is simply beautiful, a good cook and quite intelligent has no chance at all. The method of correlation of ranks chooses always extreme situations as the best choice. An in between alternative solution will never have a chance. In this way rank correlation is subjective.

Another possibility consists of giving weights to the first, second, third, etc. rank but then we end again with subjective weights. However, the introduction of a supplemental notion, the statistical term of Correlation, may help. Suppose the statistical universe is just represented by two experts nominated by two stakeholders. If they both rank in the same order different items to reach a certain goal, it is said that the correlation is perfect. However, perfect correlation is a rather exceptional situation. The problem is then posited: how in other situations correlation is measured. Therefore, the following Spearman's coefficient is used (Kendall 1948: 8):

$$
\rho=1-\frac{6 \sum D^{2}}{N\left(N^{2}-1\right)},
$$

where: $D=$ difference between paired ranks; $N=$ number of items ranked.
According to this formula, perfect correlation yields the coefficient of one. An acceptable correlation reaches the coefficient of one as much as possible. No correlation at all yields a coefficient of zero. If the series are exactly in reverse order, there will be a negative correlation of minus one, as shown in the following example.

Table B.1. Negative rank order correlations

\begin{tabular}{cccccc}
\hline Items & $\begin{array}{c}\text { Expert } \\
1\end{array}$ & $\begin{array}{c}\text { Expert } \\
2\end{array}$ & $\begin{array}{c}\text { Sum of } \\
\text { ranks }\end{array}$ & $D$ & $D^{2}$ \\
\hline 1 & 1 & 7 & 8 & -6 & 36 \\
\hline 2 & 2 & 6 & 8 & -4 & 16 \\
\hline 3 & 3 & 5 & 8 & -2 & 4 \\
\hline 4 & 4 & 4 & 8 & 0 & 0 \\
\hline 5 & 5 & 3 & 8 & 2 & 4 \\
\hline 6 & 6 & 2 & 8 & 4 & 16 \\
\hline 7 & 7 & 1 & 8 & 6 & 36 \\
\hline & & & & & 112 \\
\hline
\end{tabular}

This Table shows that the sum of ranks in the case of an ordinal scale has no sense.

Correlation leads to: $\rho=1-\frac{6 \times 112}{7(49-1)}=-1$.

The correlation for an ordinal scale is only estimated two by two. This means few chances for a perfect or even for an acceptable correlation if more than two experts, groups of stakeholders or sets of data are involved. In addition, weighing is present, namely the same weight for every item.

Mueller et al. (1970: 270) gave the example of a perfect correlation between income and monthly rental of six families. We extended this example with a set of data on the size of households.

Table B.2. Rank order of families by income, monthly rental and number of persons in the household

\begin{tabular}{ccccccc}
\hline Family & income & rank & rental & rank & persons & rank \\
\hline A & $\$ 10000$ & 1 & $\$ 250$ & 1 & 6 & 1 \\
\hline D & 7000 & 2 & 200 & 2 & 5 & 2 \\
\hline F & 5000 & 3 & 125 & 3 & 4 & 3 \\
\hline B & 4500 & 4 & 90 & 4 & 3 & 4 \\
\hline E & 4000 & 5 & 85 & 5 & 2 & 5 \\
\hline C & 500 & 6 & 70 & 6 & 1 & 6 \\
\hline
\end{tabular}

It is clear, that this perfect correlation is rather exceptional. There is even more. 
1) Another psychologist maintains that a scale from 1 to 7 is considered as a maximum to think of for the human brain (Miller 1965).

2) In ordinal ranking 3 is farther away from 1 than 2 from 1, but Kendal (1948:1) goes too far.

Table B.3. Ordinal versus cardinal: comparing the price of one commodity

\begin{tabular}{ccc}
\hline & Ordinal & Cardinal \\
\hline & 1 & \\
\hline & 2 & \\
\hline & 3 & \\
\hline $\mathrm{A}$ & 4 & \\
\hline & 5 & $6.03 \$$ \\
\hline $\mathrm{B}$ & 6 & $6.02 \$$ \\
\hline
\end{tabular}

As for Kendal, B is far away from A as it has 7 ranks before and A only 4, whereas it is not true cardinally. Once again we quote Arrow (1974): "Obviously, a cardinal utility implies an ordinal preference but not vice versa".

Despite Arrow's warning some authors show an excess of subjectivity by deducing a cardinal value from an ordinal ranking. Sometimes an Arithmetical Progression is used under the form: 0 (non-existing), 1, 2, 3, 4, $5,6,7,8,9,10$. A scale from 1 to 7 is considered as a maximum (Miller 1965). A more limited choice would be, for instance, from 1 to 4 . This range may be still too large as 2 is the double of 1 , and four equals four times one. Seldom a direct cardinal scale will show such huge jumps. Perhaps the scale 3, 4, 5 would be preferable. Zero can still be added to the scale for somebody who disapproves completely. The choice of categories remains arbitrary. To our mind, these dimensionless numerals are Cardinal Numbers. An Ordinal Scale is given by: $1^{s t}, 2^{\text {nd }}, 3^{r d}, 4^{\text {th }}$,

Saaty (1987) makes another proposition inside his pairwise comparisons: the Fundamental Scale:

1 equal importance

3 moderate importance of one over another

5 essential or strong importance

7 very strong importance

9 extreme importance
When compromise is needed, 2,4,6,8 are intermediate values between the two adjacent judgments.

Some authors go even further. Lootsma (1987) promotes the Normal Scale:

$$
\mathrm{e}^{0}=1 ; \mathrm{e}^{1}=2.7 ; \mathrm{e}^{2}=7.4 ; \mathrm{e}^{3}=20.1 \ldots
$$

This scale seems exaggerated, which is even more the case with his Stretched Scale:

$$
\mathrm{e}^{0}=1 ; \mathrm{e}^{2}=7.4 ; \mathrm{e}^{4}=54.6 ; \mathrm{e}^{6}=403.4 \ldots
$$

Anyway, the comparisons between Ordinal Scales and Dimensionless Numbers seem disputable. It is better that from the beginning as much as possible ordinal scales are avoided.

\section{Endnotes}

${ }^{1}$ As well known, statistics already existed in Roman times with the census of population.

2 At a later time, namely in 1981, Huber wrote a more complete book on Robust Statistics. In 1994 on the occasion of Huber's birthday his colleagues edited a book on Robust Statistics (Rieder 1996).

${ }^{3}$ A good overview of this problem of robustness and Bayesian Analysis is brought by Ruggeri, 2008.

4 Webster's new Universal Unabridged Dictionary: robust: strong; stronger, strongest.

5 Brauers and Zavadskas (2006), prove that the most robust choice for this denominator is the square root of the sum of squares of each alternative per objective.

${ }^{6}$ Instead of a normal increase in productivity growth a decrease remains possible. At that moment the interval becomes $[-1,1]$. Take the example of productivity, which has to increase (positive). Consequently, we look for a maximization of productivity e.g. in European and American countries. What if the opposite does occur? For instance, take the original transition from the USSR to Russia. Contrary to the other European countries productivity decreased. It means that in formula (2) the numerator for Russia was negative with the whole ratio becoming negative. Consequently, the interval changes to: $[-1,+1]$ instead of $[0,1]$.

${ }^{7}$ Brauers 2008 b proves that the Min-Max metric is the most robust choice between all the possible metrics of reference point theory.

8 This convergence of opinion has to be brought not by face-toface methods, but rather by nominal methods such as the Ameliorated Nominal Group Technique or by the Delphi Method.

For the Ameliorated Nominal Group Technique see: Brauers 2004: 44-60; 1987; Brauers and Lepkova 2002, 2003; Van De Ven, Delbecq 1971.

For Delphi see: Brauers 2008a; 2004: 40-44; Dalkey and Helmer 1963.

${ }^{9}$ Lithuanian greenhouse gas emission limited by 2020 compared to 2005 : $18,429,024$ tons of $\mathrm{CO} 2$ equivalent or $15 \%$ above the 2005 emission; cf. other Baltic States: Latvia 17\%, Estonia 11\% (Commission of the European Communities 2008c). 


\section{References}

Admati, A. R.; Pfleiderer, P. 1994. Robust financial contracting and the role of venture capitalists, Journal of Finance 49(2): 371-402.

Arrow, K. J. 1974. General economic equilibrium: purpose, analytical techniques, collective choice, American Economic Review 64(3): 253-272.

Beveridge, W. H. 1942. The Beveridge Report. His Majesty's Government. London.

Beveridge, W. H. 1944. Full Employment in a Free Society. London: Allen and Unwin.

Brauers, W. K. 1987. Nominal Methods in Group Multiple Decision Making. Research Paper No. 3. Institute for Developing Countries, University of Antwerp, Antwerp.

Brauers, W. K. 2002. The multiplicative representation for multiple objectives optimization with an application for arms procurement, Naval Research Logistics 49: 327-340.

Brauers, W. K. 2004. Optimization Methods for a Stakeholder Society. A Revolution in Economic Thinking by Multiobjective Optimization. Boston: Kluwer Academic Publishers and Springer. ISBN 1-4020-7681-9.

Brauers, W. K.; Lepkova, N. 2002. The application of the nominal group technique to the economic outlook for Lithuania over the period 2002-2011, Ükio technologinis ir ekonominis vystymas [Technological and Economic Development of Economy] 8(1): 19-24.

Brauers, W. K.; Zavadskas, E. K. 2006. The MOORA Method and its application to privatization in a transition economy, Control and Cybernetics 35(2): 445-469.

Brauers, W. K.; Lepkova, N. 2003. The application of the nominal group technique to the business outlook for the facilities sector of Lithuania over the period 2003-2012, International Journal of Strategic Property Management 7(1): 1-9.

Brauers, W. K. 2008a. Group decision making with multiobjective optimization, Foundations of Computing and Decision Sciences 33(2): 167-179.

Brauers, W. K. 2008b. Multi-objective decision-making by reference point theory for a wellbeing economy, Operations Research International Journal 8: 89-104.

Brauers, W. K.; Zavadskas, E. K. 2008. Multi-objective optimization in location theory with a simulation for a department store, Transformations in Business and Economics 7(3): 163-183.

Casella, G.; Berger, R. L. 2002. Statistical Inference. Second Edition. Duxbury Press.

Churchman, C. W.; Ackoff, R. L. 1954. An approximate measure of value, Operations Research 2: 172-180.

Churchman, C. W.; Ackoff, R. L.; Arnoff, E. L. 1957. Introduction to Operations Research. New York: Wiley.

Commission of the European Communities. 2008a. Joint Impact Assessment. SEC (2008) 85/3. Brussels.

Commission of the European Communities. 2008b. Proposal for a decision of the European Parliament and the Council on the effort of the Member States to reduce their greenhouse gas emissions. COM (2008) SEC (2008). Brussels.

Commission of the European Communities. 2008c. Proposal for a Directive of the European Parliament and the Council on the promotion of energy from renewable sources. COM version 15.4. Brussels.

Dalkey, N.; Helmer, O. 1963. An experimental application of the delphi method to the use of experts, Management Science 9(3): 458-487.

Darnell, A. C.1997. Dictionary of Econometrics. Cheltenham, UK, Edward Elgar.

Dasgupta, P.; Maskin, E. 2008. On the robustness of majority rule, Journal of the European Economic Association 6(5): 949-973.

Edin, P. A.; Ohlson, H. 1991. Political determinants of budget deficits: coalition effects versus minority effects, European Economic Review 35(8): 1597-1603.

Frisch, R. 1933. Pitfalls in the Statistical Construction of Supply and Demand Curves. Leipzig: Hans Buske Verlag.

Ginevičius, R.; Podvezko, V. 2004. Quantitative assessment of regional development, Environmental Research, Engineering and Management 1(27): 10-14.

Ginevičius, R.; Podvezko, V.; Mikelis, D. 2004. Quantitative evaluation of economic and social development of Lithuanian regions, Ekonomika 65: 1-13.

Hays, W. L. 1974. Statistics for the Social Sciences. London: Holt, Rinehart and Winston.

Heckman, J. J.1992. Havelmo and the birth of modern econometrics, Journal of Economic Literature 30: 876-886.

Hoel, P. G. 1971. Elementary Statistics. New York: John Wiley.

Huber, P. J. 1969. Theorie de l'Inference Statistique Robuste. Montreal: Les Presses de l'Université de Montreal.

Huber, P. J. 1981. Robust Statistics. New York: Wiley.

Intriligator, M. D. 1978. Econometric Models, Techniques and Applications. Amsterdam: North-Holland Publishing Company.

Karlin, S.; Studden, W. J. 1966. Tchebycheff Systems: with Applications in Analysis and Statistics. New York: Interscience Publishers, 278-280.

Keeney, R. L.; Raiffa, H. 1993. Decisions with Multiple Objectives, Preferences and Value Tradeoffs. Cambridge: University Press.

Kendall, M. G. 1948. Rank Correlation Methods. Griffin London.

Kendall, M. G.; Gibbons, J. D. 1990. Rank Correlation Methods. London: Edward Arnold.

Kennedy, P. 1998. A Guide to Econometrics. Oxford: Blackwell.

Kreps, D. M. 1990. Game Theory and Economic Modelling. Oxford: Oxford University Press and Clarendon Press.

Lootsma, F. A. 1987. Numerical Scaling of Human Judgement in Pairwise-comparison Methods for Fuzzy Multi-criteria Decision Analysis, in Proceedings of the NATO Advanced Study Institute. Val d'Isère, France, July 26 - August 6. 
Machina, M. J.; Schneider, D. A. 1992. More Robust Definition of Subjective Probability, Econometrica 60(4): 745-80.

Matyas, L.; Sevestre, P. 1992. The Econometrics of Panel Data. Handbook of Theory and Applications. Boston: Kluwer Academic Publishers.

Mažeikių nafta. Available from Internet: <www.nafta.1t/en/ content.php?pid=34>.

Mendershausen, H. 1949. Future foreign financing, Review of Economics and Statistics November: 272-274.

Miller, G. A. 1965. The magical number seven plus or minus two: some limits on our capacity for processing information, Psychological Review 63: 81-97.

Mills, J. A. 1992. Bayesian Prediction Tests for Structural Stability, Journal of Econometrics 52(3): 381-388.

Mueller, J. H.; Schuessler, K. F.; Costner, H. L. 1970. Statistical Reasoning in Sociology. Second Edition. Boston: Houghton Mifflin.

Pigou, A. C. 1920. The Economics of Welfare. Fourth Edition. London: Macmillan.

Polak, J. J. 1954. IMF, Conceptual Problems involved in projections of the international sector of Gross National Product, Long-Range Economic Projection. Princeton, Princeton University Press.

Rhodes, G. F.; Fomby, T. B. 1988. (Eds.). Nonparametric and Robust Inference. Greenwich, CT: JAI Press.

Rieder, H. (Ed.). 1996. Robust Statistics, Data Analysis and Computer Intensive Methods. New York: Springer.

Ruggeri, F. 2008. Bayesian Robustness, Newsletter of the European Working Group "Multiple Criteria Decision Aiding” 3(17): 6-10.
Saaty, T. L. 1987. What is the Analytic Hierarchy Process? In Proceedings of the NATO Advanced Study Institute. Val d'Isère, France, July 26 - August 6.

Särndal, C. E.; Swensson, B.; Wretman, J. 1992. Model Assisted Survey Sampling. New York: Springer.

Spearman, C. 1904. The proof and measurement of association between two things, The American Journal of Psychology 15: 72-101.

Spearman, C. 1906. A footrule for measuring correlation, British Journal of Psychology 2: 89-108.

Spearman, C. 1910. Correlation calculated from faulty data, British Journal of Psychology 3: 271-295.

Statistics of Lithuania. 2006. Counties of Lithuania. Department of Statistics to the Government of Lithuania. ISSN 1648-0260.

Stigler, S. 1973. Simon Newcomb, Percy Daniell and the History of Robust Estimation 1885-1920, Journal of the American Statistical Association 68: 872-879.

Thomas, R. L. 1985. Introductory Econometrics. London: Longman.

Tinbergen, J. 1930. Bestimmung und Deutung von Angebotskurven, Zeitschrift für Nationalökonomie 1(1): 669-679.

U. S. Department of Commerce. 1951. National Income and Product of the U.S. 1929-1950.

Van De Ven, A. H.; Delbecq, A. L. 1971. Nominal versus interacting group processes for committee decision-making effectiveness, Academy of Management Journal 14(2): 203-213.

Vincke, P. 1999. Robust solutions and methods in decision aid, Journal of Multi-Criteria Decision Analysis 8: 181-187. Wonnacott, R. J. and Wonnacott, T. H. 1970. Econometrics. New York: Wiley. 